\title{
Radio, Web-Radio and Podcasting in Greece: Past, Present and Futures Dr Evi Karathanasopoulou
}

Dr Evi Karathanasopoulou, Senior Lecturer in Audio Production, Bournemouth University

evik@bournemouth.ac.uk

\begin{abstract}
Author Biography:
Dr Evi Karathanasopoulou is a Senior Lecturer in Audio Production at Bournemouth University, UK. She works across theory and practice in the field of Audio Media. She studied classical music in Athens- Greece before moving to the United Kingdom where she gained a 1st class (Hons) BA in Media Production: TV \& Radio from the University of Sunderland and an MA in Radio from Goldsmiths College. She gained her Ph.D. at the University of Sunderland, researching radio as an intimate medium, while also teaching across undergraduate and postgraduate Media courses there. Her doctoral work sets out a typology of radiophonic intimacies. Her latest theory output is an interdisciplinary article on the concept of atmosphere in radio and architecture. Her latest practice output is Air Free, an audio installation artwork created as part of an international collaboration with the Goethe-Institut.
\end{abstract}


Radio, Web-Radio and Podcasting in Greece: Past, Present and Futures

ABSTRACT:

Notes for Chapter Authors:

Your abstract can be Structured or Unstructured, please follow advice from your Volume Editor Insert abstract

\section{KEYWORDS:}

(Please supply up to 6 keywords for your Chapter)
1. Podcasting
2. Radio
3. Web-radio
4. Radio Studies
5. Audio Media
6. Greece 
Radio, Web-Radio and Podcasting in Greece: Past, Present and Futures

\section{Main Body:}

\section{Introduction}

A book chapter about Greek radio cannot begin without stating what is perhaps obvious: this is a relatively under-researched field. Indeed, until recently this was something that one needed to state in any academic work about radio in general (Lewis 1989; Shingler \&Wieringa, 1998; Lewis, 2000; Lacey, 2008; Gazi, Jędrzejewski \& Starkey, 2011; Karathanasopoulou, 2014). However, in recent years the field of radio and audio studies is flourishing along with the expanding field of audio media which is re-emerging as part of mobile and immersive media technologies. And while not extensive, some of the already existing important writing about Greek radio will form the basis of this chapter.

Now, in the new but established field of radio studies we are starting to see and engage with the nuances that are revealed the longer we study the medium. Thus, the question arises about whether there is such a thing as a unified 'radio', or whether the nuances within the different emerging audio forms and formats, call for a more concentrated approach to each of those. One of the most dominant such new formats is the podcast. Llinares, Fox and Berry, in "the first comprehensive interdisciplinary collection" on podcasting, claim that we should be concentrating not only on the things that linear radio and podcasting have in common; but in those things too that make them different (2019: 3-5). The question one might ask is then, why I chose to start this chapter on podcasting by talking about radio. Kate Lacey writes that "this single word, radio, is called upon to describe any number of different things - material, virtual, institutional, aesthetic, experiential" (2018: 110). Her use of the word 'radio' allows for a holistic approach in which radio is viewed as an "intellectual artefact" (2018: 110-11). In order then for us to trace along the Greek case for audio media, I shall begin from this holistic approach, by exploring some histories and established structures in order to later arrive at Llinares, Fox and Berrys' approach, where the nuances and particularities of podcasting become very important on a socio-political level. As there is very little to no writing on Greek podcasting, this chapter will attempt to provide a broad snapshot of the present landscape; this snapshot is by no means exhaustive or ultimate.

This chapter, in its restricted scope and length, will attempt to look at the extent to which podcasting is part of Greek media, the connections between podcasts, traditional broadcast radio and web-radio, and the potential futures of podcasting within the challenging terrain of the Greek media landscape. Podcasting's potential to be ground-breaking will be pertinent in the discussion 
here. We will be seeing how what is sometimes described as a chaotic and clientelist media environment, created in Greece after media deregulation in the late 80 s, has left an empty space with an urgency to be filled by independent voices (Sims, 2003; Barboutis \& Baltzis, 2012; Papadopoulou, 2019). We will be looking at how Llinares, Fox and Berrys' case for podcasting as a medium "more radical, and more culturally urgent than radio" gains traction in a context like the Greek one (2018: 2). While much of the writing on Greek radio that this chapter will be referencing is about the news media, this chapter is taking a different approach in looking at radio as a whole. It will be looking at radio as a space with the ability to foster cultural, societal and political growth, irrespective of genre or type of programming. Various examples will be used from different types of outlets and programming in the spirit and belief that culture, as well as politics, and the free, rich in content and unbiased coverage of it in the media, can also foster societal and political change.

Starting with a case study of a popular radio station we will be tracing a path along FM Radio and the effect of playlists onto plurality and diversity of content. We will then be looking at web-radio and how, while it may be seen as antidote to that lack of diversity, financial structures and advertising traditions in Greece may render it non-viable. Finally, we will be looking at the current state of podcasting in the country, often by considering a lack of understanding of its nuances as a new medium; but eventually looking at potential positive futures.

\section{The case of Melodia 99.2 - Playlists versus Presenters}

According to Papathanassopoulos, today "radio remains an important source of information and entertainment for the Greek people", with the overwhelming majority of stations broadcasting on FM and most of them also broadcasting their content on the web (2018). He notes, however, that these stations operate in a precarious existence both due to an uncertain, abstract licensing context and the collapse of advertising expenditure due to the fiscal crisis (2018). Around eleven years ago, during the beginnings of the Greek economic crisis, Agas, Tsourvakas and Rekaiti were warning that the low cost of radio advertising is "problematic for radio as it may lead to strategies that lower costs, which in turn may lead to problems of differentiation with content, service quality, and less innovation and creativity when using new technologies and developing new products" (2009: 114). Their predictions indeed somewhat materialised, as in the preceding decade we have witnessed some closures as well as some stations radically reducing their production of original content and relying on music playlists instead - these may either be prepared to be played by a computer 
without the presence of a presenter or they may be implemented by the management of a radio station and imposed upon presenters to play during their shows.

One example of the latter is music station Melodia 99.2, also previously known as Melodia FM, which on its heyday, in 1996, had one of the biggest shares of the advertising revenue in the Athenian radio market (Agas, Tsourvakas \& Rekaiti, 2009: 107-108). While Melodia 99.2 is still one of the strongest players in the Greek radio market, its content has indeed suffered (E-tetRadio, 2020). In 2001, the station offered presenter-led content almost 24 hours a day and was employing twentythree presenters-producers (e-tetRadio, 2017). Today, following a series of redundancies which started in 2010, the station offers authored content only on weekdays and only between seven in the morning and ten in the evening. It now employs a mere five presenters-producers (E-tetRadio, 2020; Melodia 99.2, 2020).

What happened to those laid off by Melodia 99.2 may be an indication of potential futures in terms of independent content but also a cautionary tale of the difficulties faced by those wanting to create new digital spaces for audio content in Greece. During my research for this chapter I interviewed Olga Laskaratou, a presenter-producer of an eclectic music programme at Melodia 99.2 who later became one of the founders of toradiofono.gr - an independent web-radio initiative set up by those broadcasters that were responsible for Melodia 99.2's reputation during its heyday. Laskaratou is also known for her work for SKAI 100.3, where she produced diverse, and rear in Greece, content that went beyond the typical music and news output. Laskaratou's case and own take on what happened is illuminating and somewhat links the concern about advertising, posed by Agas et.al in 2009, to the playlist radio model, which Laskaratou describes as a "financial model" (Laskaratou, 2020).

The online publication MusicPaper.gr reported on Laskaratou's exit from Melodia on March 312011 in an article which they illustrated with a picture of the logo of the station with a red line striking through the name 'Melodia' and replacing it with the word 'playlist' in red type; a bold reference to the links between cutting down costs and a lowering of the quality and diversity of radio content (MusicPaper.gr: 2011). Melodia's new model was based on management implemented playlists, played either by computers or by the few presenters that remained at the station, rendering the presenter - producer a voice that would be there to merely advertise products, give out free promotional tickets to events and convey practical information such as weather and traffic (Laskaratou, 2020). The idiosyncratic, eclectic character that had made Melodia 99.2 so popular, was 
based on presenter personalities who each brought with them a mix of Greek and non-Greek music often mixed with poetry, literature and intelligent conversation. The new model only features Greek music and is no longer based on the way that a presenter's personality can be reflected onto the actual content of a programme. Apart from a diminishing of the presenters' role as a creative force in the station, Laskaratou remarks that before being made redundant, the presenters had already taken pay cuts (2020). The article in the MusicPaper.gr also makes a point to remark that at the time of her dismissal, Laskaratou was not well-paid (2011). Laskaratou's proposal that the playlist model is a financial model is based on the fact that a knowledgeable broadcaster who will bring their own niche and character into a station, is expensive; and also, crucially, their expertise is rendered redundant, as the playlists will already have been selected by the station's management and the content of a programme pre-decided (Laskaratou, 2020). The speech content between songs is directed, according to Laskaratou, at a work-place audience, or audiences at cafes and restaurants, who want the music to act as a pleasant background and the presenter as a non-demanding of attention, familiar voice (2020).

During my interview with her, I found out that, as this book chapter is being written, Olga Laskaratou is herself conducting research and working on a film documentary about playlist radio in Greece, looking at how this has affected Greek radio and also Greek recording artists and their record labels and the music they choose to create. According to Laskaratou, in order to be played by these stations, record labels will opt to record music that we neatly fit into the playlist model (2020). This diminishes diversity in output and new artists find it very hard to have their music played by these stations (Laskaratou, 2020). Laskaratou's own interest and research into the matter makes her perspective here even more relevant. Her remarks on programme content and on how the playlist radio model as a financial structure affects the type of music actually released by record labels - who will agree deals with playlist radio stations (2020)- brings us back to the discussion about culture, society and politics all being wrapped up together when it comes to the media. Plurality, not only in political speech, not only in a diversity of voices, but also in the type of art that is being promoted is extremely important for a healthy media system in any country. Based on Laskaratou's insight, one might argue that, the playlist model, while perhaps seemingly non-threatening at first glance, can be deeply problematic. 
Radio, Web-Radio and Podcasting in Greece: Past, Present and Futures

\section{Web Radio: From Melodia FM to toradiofono.gr}

In 2013, Olga Laskaratou along with two ex-employs of Melodia 99.2 (presenters Christos Papamichalis and Christos Kortselis) created the Web-radio station toradiofono.gr; and a number of those heavyweight presenters-producers that had been the spearheads of the unique programme of Melodia 99.2, quickly joined (2013). Odysseas loannou, who had been the Melodia FM station manager during its most successful period, also later joined the toradiofono.gr team. The web station was meant to provide the uniquely curated and presented content that Melodia 99.2 had previously been offering. Laskaratou describes toradiofono.gr as an attempt to create a space to make the type of radio the team wanted to make; the main idea was to bring the "vintage", nostalgic aesthetic of what radio used to be into the new era of the web (2020). The branding of the station reflected this idea and was carefully designed by the station team and Petros Paraschis - a well-known graphic designer in Greece.

Much of the discussion around toradiofono.gr here stems from the hindsight of its eventual demise around 2018. Thus, while the discussion here might appear to be slightly negative at times in terms of web-radio viability, it is actually intended as a summation of the lessons that can be learned and perhaps used in similar ventures in the future. Laskaratou, in our discussion summarised the issues faced by the station under four interconnected categories: financial non-viability, audience reach, lack of visual content and internal structural challenges. We will be looking at these here in a little more detail.

Financial Issues, Advertising, Crowd-funding

The main problem of the station was that advertisers did not want to invest in what seems to still seen as a 'new medium' in Greece. In my interview with her, Laskaratou ascribed the hesitance of advertisers in a lack of understanding of how web-radio works (2020). She noted that advertisers would compare the clicks a web-radio page received to the vastly bigger in numbers clicks that a news website receives; a comparison which, while on the surface might seem logical, is unfair and does not consider the vast differences between what are essentially two different media - merely accessed via the same technology.

Interestingly and perhaps ironically, the thing that seems to make web-radio commercially untenable in Greece, is the thing that audiences seem to value the most. During 2011-2012 (roughly 
Radio, Web-Radio and Podcasting in Greece: Past, Present and Futures

a year before the establishment of toradiofono.gr), Gazi, Cordeiro, Starkey \& Dimitrakopoulou were conducting a European survey in Greece, Cyprus, UK and Portugal, which documented how a young generation of early adopters of technological innovation accessed new technology and their usage of new and established media (2014: 247). Their data from 224 participants for Greece and Cyprus (which were combined due to a cross-over between populations), shows that:

“the most popular reasons for listening were 'fewer commercials' (65.5\% in Greece/Cyprus), being able to access 'more music variety' (28.9\% in the UK; $49.7 \%$ in Greece/Cyprus), and control over the music played (49.7\% in Greece/Cyprus)" (2014: 249).

It is then fair to wonder, if and when advertisers catch up to web-radio, how Greek audiences might react to a possible increase in advertising. Yet, the second reason posed by the survey participants above is more positive and in-line with what toradiofono.gr had set out to do. Namely, offer music variety and content diversity, untethered from a system where the music played is the result of financial deals between record labels, radio stations and advertisers. Additionally, the survey indicated "continuing high levels of dependence on radio as a discovery medium" for new music, placing it "second only to searching the web" (2014: 252); a function connected to traditional broadcast radio as we remember it from the past and relevant to the nostalgic remit of toradiofono.gr.

It would be very interesting to see what a similar audience survey would show today and to what extent the data might have already changed; especially, given the rapid change and convergence of the media globally and the concurrent shifts in audience listening habits, internet usage and interaction with the media via social media.

Laskaratou mentions that there was an attempt for crowd-funding which was, however, done ineffectively due to the team's hesitance to be seen to ask the audience for financial support (2020). It is important here to remind the reader that this would have been during an ongoing, bitter financial crisis, which had impacted in one way or the other most of the population in Greece. At the time, the concept of crowd-funding would have been a fairly new concept in the country but the awkwardness felt by the station's team would be mostly related to a sense of priorities and expectations when it came to what they could reasonably hope to receive from their audience. Much of the financing for the station came from parties and concerts organised by the station and with the support of some major Greek artists. 


\section{Visual Content and Audience Reach}

Laskaratou, as a criticism of how the core team of the station responded to their new brief of creating a successful web-station, cites the lack of an adequate visual presence - such as studio webcams, particularly when interviewing famous guests (2020). Liz Gould, notes that while accompanying visuals do not really alter the main content and style of a radio programme, visual recordings or radio programmes can stretch "the traditional parameters of audio broadcasting by augmenting 'radio' with 'pictures'" (2009: 103). The multi-platforming of such content could have indeed been beneficial to this web-radio station and potentially have assisted in attracting advertisers, while not really sacrificing the station's main remit for eclectic content.

Crucially, Laskaratou talks about web-radio being a different medium than traditional broadcast radio (2020); echoing here Llinares, Fox and Berry's argument on podcasting (2018). She positions this argument within a technological context and how this affects audience reach. Namely, while one of the main goals of the station was to carry with it Melodia 99.2's big audience, Laskaratou notes that this was not feasible due to the fact that much of that audience was not as well-versed with the internet (2020). She also notes, that not yet having the technological ability to have internet radio in cars further restricted their audience (2020). Richard Berry, writing around the same time when toradiofono.gr was taking its first steps, confirms that one of radio's most successful traits is that it is highly portable and that internet radio is hindered in this way (in Oliveira, Stachyra \& Starkey, 2014: 6). He notes, that despite faster mobile internet speeds, the cost of using mobile internet to listen to the radio remains high (in Oliveira et al. 2014: 6). Referencing Johnson (2012), Berry remarks that due to costs and still imperfect internet coverage, "mobile web is not yet ready to replace broadcast platforms as our primary source of radio listening (in Oliveira, Stachyra \& Starkey, 2014: 6). In that way, this is perhaps not a problem unique to Greece, but it positions this Greek example within a wider context of an industry still evolving and with many unknowns.

\section{Internal Structure Tensions and the idea of Radio as Aural Archive}

The financial struggles in the station and the inability of the core team to concentrate all of their time to the station, lead to the idea to bring in and train some of the listeners as additional presenters- producers who became part of the programming rota (Laskaratou, 2020). This was in order to allow some respite for the core team who had gone from being one of the most well-known 
Radio, Web-Radio and Podcasting in Greece: Past, Present and Futures

programme teams in Greek music radio to working unpaid at toradiofono.gr (Laskaratou, 2020). Interesting questions arise here in terms of the tensions between, on the one hand, web-radio and podcasting often being seen as a democratised means for the audience to become producers and, on the other hand, the need for professionally created diverse web-based content with high production values and wide reach. This idea is not dissimilar to the culture of audience participation in podcasting. Within a converged media landscape, we are increasingly likely to witness tensions between those traditionally seen as professionals and a new generation of broadcasters who in the past would either have not had access to production or would be merely considered amateurs. Markman notes that,

"One of the defining features of convergence is participatory culture, where the boundaries between producers and consumers are increasingly blurred, and consumers are active participants, rather than passive spectators" (2012: 549).

There are obvious advantages to an audience that actively participates. The participation of the audience in what was meant to be an independent and idealistic but for-profit venture presented a set of further complications for the station. While this participation may have been a respite for the core team in terms of time and financial pressures, those presenters would not have the experience needed in order to truly sustain and, importantly, evolve the station's content according to its two main but conflicting needs: to provide diverse, high quality content but do it in such a way that it becomes attractive to advertisers.

Toradiofono.gr eventually fizzled out around 2018 as those that set it up could no longer sustain the lack of financial reward with the heavy workload that the high-quality content they aspired to required (Laskaratou, 2020). But the venture remains one of the most significant web-radio stations in Greece.

An example of an online only radio station currently operating in Greece is Offradio.gr. Founded in 2008, they describe themselves as "the leading independent online radio station in Greece" (2020). They note on their web-page that in 2011 they achieve an "e-Award as the best web radio in Greece" (2020). The station's Facebook page has over thirty-three thousand followers. Apart from streaming, the webpage of the station contains a chat service, links to their own playlists, and link to download their own mobile app. The station also creates a podcast, in which they repurpose some 
of their shows as podcasts for those who may have missed or want to listen again to content that was initially live-streamed. Interestingly, the webpage does not directly link to the podcast.

While a very useful case-study for the purposes of this chapter, it should be noted that toradiofono.gr was not the first relatively high-profile web radio station in Greece. Mindradio.gr was one of the earliest and most promoted examples of a web-only radio station. Created in 2007 it soon gained a major sponsorship from one of the largest mobile telephony companies in Greece, Cosmote; and itself sponsored and covered some big cultural events, mainly in Athens. Its content was varied and relatively diverse for that time period, while firmly focused on music and the arts. It offered a combination of professional presenter- producers as well as audience generated shows. Both professional broadcasters and audience members who were chosen to produce and present shows could do this from their own homes by downloading a simple piece of software and remotely connecting to the station's servers. The webpage of the station featured a bespoke chat service that allowed for the listeners to communicate with the presenters as well as with each other. Importantly, the webpage of the station, repurposed interview packages with Greek and foreign artists (in music, theatre, cinema and so on) as downloadable audio. At the time the RSS technology was still very new and thus not at all used or exploited. While these stream-able features were not podcasts, they were quite unique at the time in Greece.

Mindradio.gr was also short-lived. perhaps again as a result of similar tensions to do with finances and disparities between professional and user-generated content. With most of its digital footprint deleted from the internet, the researcher struggles to fully record its history. It may seem paradoxical, that while, for example, there exists a big archive of $E R T^{\prime} s$ broadcast radio content from the past 70 years (as we will see later in this chapter), Mindradio.gr's "born-digital audio content" has been lost (VanCour, 2016: 400). But, according to VanCour, traditional understandings and expectations of what has been termed "broadcast content" has led to the exclusion from archiving content created for content such as podcasts and internet radio (2016: 399-400).

In my interview with her, Laskaratou noted that while working at toradiofono.gr, what she felt really was missing from it was the idea of radio as a medium which creates aural archives (2020). Her prior work for the radio station of $S K A I$, a major news and current affairs organisation in Greece, had taught her that speech programming, drama and documentary, and not music programming, are those things that make radio very important - here she posits an interesting distinction between the extremely important, yet fleeting, familiarity of everyday radio content such as music programming 
and the unique aural heritage that radio is able to, not only preserve, but create. Before the eventual demise of toradiofono.gr, Laskaratou notes that she started a poetry series, recording the voices of major Greek poets such as Kiki Dimoula and Katerina Anghelaki-Rooke (2020).

Podcasting is perhaps a better fitted venue for those who, like Laskaratou, see radio not only as a business but as an important, noble, cultural cause. As we will see in the next part of this chapter, due to funding models and a public-interest remit, traditionally it has been the public broadcaster in Greece that has been able to create important cultural archives. Today, podcasting may be a way to add to, enhance and renew this idea of radio as a preserver and creator of cultural archive and memory.

\section{Podcasting}

"The podcasting phenomenon began in 2004" (Markman, 2012: 547). This was not long after the iPod was launched in 2001 and we may look at this timeline as a good example of how listening technologies impact content creation and formats when it comes to radio and other media. While the Walkman brought mobility and privacy into the listening experience, radio content could only be listened to live. The iPod then, adds a crucial, temporal, element to the equation: on-demand access. And with the removal of liveness, the experience of audio in space also becomes smoother - as we saw earlier, mobile phone coverage is a restrictive factor to web-radio. In 2007, Michael Bull was praising the new iPod device for offering the user "the untethered auditory freedom of movement from home, to street, to automobile, to office" (2007: 3). That same year the first iPhone was launched. Mobile phones would eventually leave behind devices such as the iPhone and other MP3 players and make on-demand listening an even simpler and accessible activity. This accessibility, along with the internet and cheap recording technologies helped popularise podcasting. Current audio technologies allow the audience to access content in an on-demand basis but, crucially, also allow anyone with a computer to make a podcast and share it with the world. A large number of podcasts were and are still made by radio enthusiasts who are not professionals (Markman, 2012: 549). As we saw earlier when discussing web-radio, allowing users to become part of a station's live web-casting was indeed a first step into giving listeners in Greece unprecedented opportunity and access to participate, not forgetting here the popular in Greece genre of the phone-in, but recognising that the phone-in merely "creates the illusion of radio as a two-way medium" (Crisell, 1994: 189). In the examples of Greek web-radio examined here, the audience is more actively 
creating content, but this still typically happens within the constraints of an organisation that is run by professionals (as we saw earlier in this chapter, MindRadio.gr and later toradiofono.gr in Greece offered this opportunity).

Richard Berry argues that with podcasting "No one person owns the technology and so it is free to listen and create content, thereby departing from the traditional model of 'gate-kept' media and production tools" (2006: 145-146). The convergent nature of podcasting is described as disruptive (Berry, 2006: 144) and "participatory" (Markman, 2012: 549). And while it is still early to make definite statements, this is what we are beginning to see in Greece, from the bottom up.

"The case of Greek radio is clearly one of late development", argued Baltzis and Barboutis some seven years ago, when considering the potential of web-casting in Greece (2013: 57). Today, while web-only radio did not really take off, broadcast radio stations can all be listened to online and have a web-presence - the latter varies in quality of content. This chapter argues that podcasting could be a late bloomer. Namely, the current landscape of podcasting in Greece appears to be sparse and disjointed. Yet, the seeds seem to be there for something more substantial to grow in the next decade. While exploring Apple Podcasts, Google Podcasts and Spotify, one will find a few dozen results. These are almost exclusively factual in nature, including music, news and current affairs, history, lifestyle, sports and technology.

\section{Amateur/Independent Podcasting}

Many podcasts from Greece or by Greeks currently belong to the amateur category. Within the Greek context this is significant, particularly if we consider that some academic approaches to the Greek media industry so far have documented radio as a venue which is merely used for the offsetting of depts via giving away advertising and as part of a climate where the media is "interweaving with political and economic interests" (Barboutis \& Baltzis, 2012: 121; Heretakis, 2011: 4, 29-30; Karamanis, 2003: 122-26; Barboutis, 1997: 3). Amateur podcasting may then be seen as a means of returning the audio medium to the people. A return that was prophesized very early on, in 1932, by Bertolt Brecht who professed that radio had to understand,

"how to receive as well as to transmit, how to let the listener speak as well as hear, how to bring him into a network instead of isolating him. Following this principle the radio should 
Radio, Web-Radio and Podcasting in Greece: Past, Present and Futures

step out of the supply business and organise its listeners as supplies" (Brecht in Silberman, 2000: 42).

While the times that this was written might have characterised this listener-producer as male, in modern Greece we find of course that amateur content is created by both male and female podcasters. The scope of this chapter does not allow me to get into an exhaustive list, however, it is important here to provide an indicative general snap-shot view of amateur/independent podcasting as this exists in Greece in 2020. There is a variety of genres available such as: Comedy (M $\alpha \rho \mu \varepsilon \lambda \alpha \dot{\delta} \alpha$

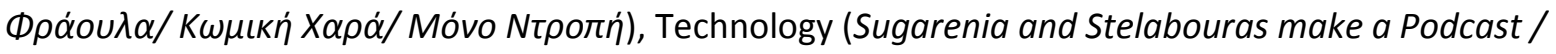

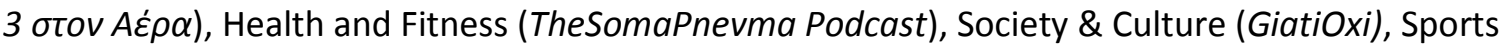

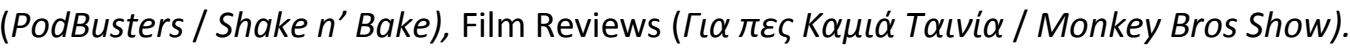

A well-produced, well-listened example here is The Brain Hacking Academy, a self-help podcast by Fyllis Gavriilidou and Dimitris Gkiokas. It was established in January 2019 and episodes are published weekly. The website of the podcast features reviews from the audience and the podcast's Facebook page has over one thousand followers - a number that may not seem big but is significant in a relatively small market such as the Greek one. The podcast's episodes feature a different theme each week and consist of topical dialogue between the two hosts. The podcast does not appear to be receiving external funding or feature advertising but does prompt the listeners to leave positive reviews online in order to help widen their community.

All of the podcasts mentioned here rarely feature anything more than dialogue between presenter or interviews. Actuality or sound effects are very sparsely used if at all. The overall style is rather stripped back and at times would benefit from better sound recording, editing and structuring. Yet, given that in the Greek media landscape podcasting is a relatively new medium and these are mostly amateur productions, this stripped-backed aesthetic and production style is to be expected and the relative variety in content is encouraging.

\section{Big Media Outlets and Podcasting}

There are a few podcasts that originate from large media organisations, like for example, Real FM's upload and repurposing as podcasts of the radio shows by famous journalist Liana Kanelli. These are available via platforms such as Apple Podcasts, Spotify and the station's own webpage. Another 
Radio, Web-Radio and Podcasting in Greece: Past, Present and Futures

representative example here, is SKAI 100.3's Greek history series sponsored by Rolex. A listener here will find original content such as interviews with experts, which is a rarity in Greek podcasting today. The content is heavily historical and presented in such a way that would attract older audiences. The content is downloadable via SKAl's on webpage and on apps such as iTunes and Google Podcasts. Interestingly the station offers a help page on how to subscribe to their podcast. The need for this may be seen as a sign of their audience's relevant lack of familiarity with podcasting. The type of advice given is reminiscent of the very basic advice that American listeners needed in 2014, when This American Life launched their spin-off show Serial which was to become the first podcast to go viral (Bishop, CNBC, 2014). At the time of launching Serial, Ira Glass, producer and host of This American Life posted a YouTube video featuring himself and an eighty-five-year-old friend of his, in order to help people understand how they can download a podcast (How to Listen to a Podcast, 2014). Helping the listeners understand the new medium is important. A year later, following the success of Serial, which at that point had reached seven million downloads, Ira Glass remarked that "Finally, this year we seem to have left the era when telling someone about a podcast got you blank stares or a confused 'HOW do you hear one of those things?'” (in Abel, 2015: ix). In Greece the audience and indeed media organisations do not seem to be quite there yet.

\section{Public Radio and Podcasting}

As in the case of the $B B C$ in the United Kingdom and NPR in the United States, it may be expected that the Greek public broadcaster will have the ability to produce diverse content that commercial stations might not be able to support. ERT does indeed feature a section on their webpage for 'web radio'. The audience here can listen their broadcast content live, but can also listen back to specific programmes repurposed for online, on-demand listening. The pages of $E R T^{\prime} s$ various stations archive their own material in this way and make it available for streaming; but navigating these pages and finding this content is rather labyrinthian and not simple for the user. Furthermore, the material is not downloadable or available through podcast apps. This restricts this content to streaming from the internet, which is not intuitive and not ideal for mobile use. It may be argued that the national broadcaster has not yet understood the new medium. What is called 'web radio' by ERT, and other broadcasters in Greece, seems to be a very dated concept. While one might argue that these stream-able programmes could be podcasts, the lack of ability to download, received via RSS, keep and play them without the need to use mobile data and via a clunky webpage, does not allow them to qualify as such. One of Berry's definitions for podcasting puts the RSS feed technology at the centre of this new medium's identity. He writes that, 


\begin{abstract}
"Portable media devices, such as the Apple iPod, are now commonly seen in use on commuter trains, buses and in the high street and each user is hungry for content. What Podcasting does is to combine these devices with online audio content (such as the material already offered by Audible) and RSS feeds as a distribution system" (2006: 145).
\end{abstract}

The public broadcaster could use podcasting not only for new material but as an accessible to all open source archive. This is particularly pertinent here, as $E R T$ holds in its archives a large amount of important work that is iconic and crucial to Greek media and cultural history. As an example, we might look at the case of radio drama (which currently is not produced on public, commercial, web or podcasting outlets in Greece).

That drama is not really part of the current podcast landscape in Greece is not surprising as it has not really been a part of Greek radio for decades. However, ERT, sometimes still plays repeats of radio drama productions from previous decades (1950s, 1960s, 1970s). These were characterised by high production standards and were created and acted by some of the most important cultural figures in Greece. While $E R T$ 's webpage contains photographic archives from the recordings of this work and a list is available to browse, this work is not stream-able or downloadable. And yet, there is evidence that there is a public appetite for these. Between 2006-2011 ERT published these as CD's and they were distributed along with a popular newspaper as an offer to its readership. These CD's, along with some other archival recordings now exist as a YouTube playlist created by a private user and is collated from the uploads of a number of other private users. Some of these recordings, uploaded between 2011 - 2017, have tens of thousands of views; an indication that an online audience would be interested in these (YouTube, 2017). ERT could capitalise on this in making these available as a podcast. This could make the material accessible to a younger audience and it could be a relatively easy entry-point for ERT into podcasting. Furthermore, it would help ERT better perform its function as a public service. Their current web-presence, while rich and at times impressive, seems to be nonintuitive and not user-friendly and crucially in some level of confusion with regards to digital formats. 
Radio, Web-Radio and Podcasting in Greece: Past, Present and Futures

\section{Self-Managed Initiatives and Podcasting}

Within the space of "self-managed and collectively organized journalistic initiatives" Infowar is an interesting example (Siapera, Papadopoulou \& Archontakis, 2015:459). Along with written and video content, the collective also produces a factual podcast series. This is available to stream through their website but importantly it is also available via podcast services (Apple Podcasts, Google Podcasts, Spotify). The episodes start with a crowdfunding campaign message for the collective, but only after informing the listener that they can listen for free. We noted earlier, that those working in toradiofono.gr, despite it being an independent commercial venture, felt uneasy when it came to crowd-funding. Similarly, there may be a tension here between offering a free independent service but also being able to survive financially. It can be argued that this tension may lie between the intrinsic politics of the Infowar venture and the financial realities of maintaining this media outlet and its podcast.

The podcast content reflects the limited funds and a fairly amateur approach to the medium of podcasting. There is a sense of it being only a secondary output as it is only a small part of the media collective's activities. While the podcast is professionally recorded and edited and while the production values technically seem to be quite high, the content is not as impressive. This mostly includes narration, music and archive footage but not much new original content. This could have included interviews, originally recorded for and by Infowar. Given that the themes of the episodes cover a wide range of politics, history and the arts, a question arises as to why interviews and other original content have not been attempted. Given the political and social space within which Infowar operates and the fact that it is meant to be an alternative to mainstream Greek media outlet for news and current affairs, one would expect that the podcast would attempt to give voice to its community. The low costs involved in audio production, compared to video and film, could be exploited in order to make podcasts such as the one by Infowar, perfect vehicles for original, groundbreaking content.

\section{The Future of Podcasting in Greece}

Based on this overview, it is evident that a better understanding of the full abilities of sound-story telling is needed within Greek podcast creators. Some of the instances of Greek web-radio and podcasting seem to be an attempt to preserve what is perceived as pure, non-commercial radio, 
which is a noble pursuit. Some other instances seem to be operating under a limited and arguably outdated notion of amateur radio production. Some others seem to be trying to replicate broadcast radio formats and structures onto online formats. This may be due to a variety of interconnecting factors such as, luck of media literacy, limited funds or a perceived (and possibly false) sense that there is a lack of audience appetite for more diverse content. The media industry in Greece does need to gain a better understanding of web-radio and podcasting and to be able to recognise them as different media that cannot operate or feature the same content as traditional broadcast radio (Laskaratou, 2020; LLinares, Fox \& Berry, 2018). Recognising these differences will bring about the creation of niche content that will respond to new the rising appetite of specialist audiences in Greece - currently probably served by foreign language content, only accessible to those with good enough use of those languages.

In a landscape where political interference and clientelism seem to be prevalent, Greece really needs podcasting. The latter can function as a medium that independently and inclusively, creates new content, voicing the post-crisis era and preserving it for future generations. Shawn VanCour's recent work on the importance of archiving digital content is interesting in this context. He writes about American radio, and yet, his words may be applied to Greece as well:

"This, then, is the final challenge for saving the nation's radio heritage: not simply identifying existing archives and endangered materials from the past but also aiding the production of new archives that actively curate content created within the present with an eye toward needs of future historians" (2016: 400).

Namely, we need ERT's archives that contain the vast wealth of Greece's cultural past. But we also need to be creating and preserving new memories of the present.

In rather serendipitous fashion, on February 2nd 2020, just as I was nearing the completion of this chapter, I came across an interview of the young Greek journalist Daphne Karnezi (LiFO: 2020). Having lived and worked in the UK for some time, Karnezi announces that she has just formed the first Greek Podcasting company called, The Greek Podcast Project. The new company already features a 'narrative', factual podcast series by Karnezi herself, titled The Fishbowl, and two future projects are in the works: Women On Topic, created for the organisation Women On Top for the professional empowerment of women and equality in the workplace; and, Soul of Athens exploring the essence, heritage and future of the Greek capital. The venture seems to be aware of the need 
Radio, Web-Radio and Podcasting in Greece: Past, Present and Futures

described by VanCour (2016) in that it aims to capture and preserve the essence of current urban cultures in post-crisis Athens.

Listening to Fishbowl, the listener is offered original interviews with international figures, such as writer Victoria Hislop, but also, with Greek experts such as architects and museum directors, who are discussing the present and future of the Greek and Athenian cultural and physical landscapes. The podcast episodes include professionally recorded and carefully edited audio 'packages' on several topical themes each week. Apart from the original interviews, archive material is used in order to illustrate these factual stories. While there may be some instances of (possibly accidental) actuality, this is still not exploited anywhere near enough or appropriately in accordance with soundstory telling techniques widely used outside of Greece. Thus, while there is still much to be desired here in terms of production values and an understanding of audio story-telling and its components, Karnezi seems to be aware of some of the shortcomings of Greek podcasting and the lack of understanding of this new medium in Greece. In her interview with LiFO newspaper, Karnezi remarks that Greece is still behind in terms of podcast production and notes that most Greek podcasts are simply archived radio programmes; she notes that this is exactly what her and her collaborators want to change (LiFO, 2020). This is promising.

\section{Conclusion}

In this chapter I have looked at the interconnections between broadcast radio, web-radio and podcasting in Greece. Light was shed to some of the challenges faced by broadcasters in all these three areas of audio media in Greece, including, financial and creative difficulties. But we also looked at some of the positive work that is currently happening and positioned it within relevant industry and theoretical frameworks in order to consider its importance and futures. As a final note, this chapter want to bring forward the idea that podcasting can provide free space for diverse voices to be heard in Greece and thus, to truly echo and intimately preserve the lives, struggles and hopes of this current generation. 
Radio, Web-Radio and Podcasting in Greece: Past, Present and Futures

\section{References:}

Abel, J. (2015). Out on the Wire: The Storytelling Secrets of the New Masters of Radio. New York: Broadway Books.

Agas K., Tsourvakas G., Rekaiti P. (2009). 'Internal and External Competition for Advertising Revenues in the Greek Radio Market', Journal of Radio \& Audio Media 16(1), 2009, pp. 102-116.

Baltzis, A. \& Barboutis, C. (2013). Doubt is in the Air: Modeling the Comparison Between Traditional and Web Casting Radio on the Greek Case. Journal of Radio \& Audio Media, 20:1, pp. 53-67

Barboutis, C. (1997). Local radio Broadcasting in Greece: Just Meaning Business. Report submitted to the Community Media Association. London: Community Media Association

Barboutis, C. \& Baltzis, A. (2012) Casting doubts on Web Media: Can Internet Radio make a difference in the Greek Case? In: Oliveira, M.; Portela, P. \& Santos, L.A. (eds.) (2012), Radio Evolution: Conference Proceedings, September, 14-16, 2011, Braga, University of Minho: Communication and Society Research Centre.

Berry, R. (2006). Will the iPod Kill the Radio Star? Profiling Podcasting as Radio. Convergence, 12(2), 143-162.

Bishop, K. (2014). How 'Serial' is making podcasts mainstream. CNBC, 14 November 2014. Accessed 5 February 2020

Bull, M. (2007). Sound Moves: Ipod Culture and Urban Experience. Oxon: Routledge.

Crisell, A. (1994). Understanding Radio. London: Routledge.

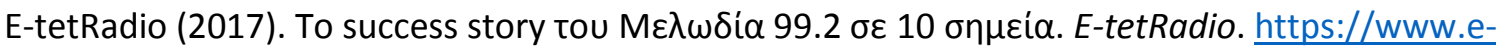
tetradio.gr/Article/14704/to-success-story-toy-melwdia-992-se-10-shmeia. Accessed 31 January 2020.

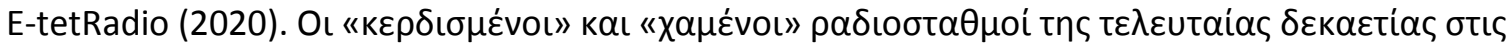

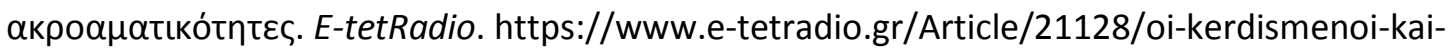
hamenoi-radiostathmoi-ths-teleytaias-dekaetias-stis-akroamatikothtes . Accessed 31 January 2020.

Gavriilidou, F. \& Gkiokas, D. (2019 -). The Brain Hacking Academy [podcast]. Available at: https://brainhackingacademy.gr/. Accessed 17 February 2020.

Gazi, A. Jędrzejewski, S. \& Starkey G. (2011). Radio Content in the Digital Age: The Evolution of a Sound Medium. Bristol: Intellect Books.

Gazi. A., Cordeiro, P., Starkey, G. \& Dimitrakopoulou, D. (2014). "Generation C" and audio media: a crosscultural analysis of differences in media consumption in four European countries.

Participations: Journal of Audience and Reception Studies, 11 (2). pp. 239-257.

Heretakis, E. (2011). Towards the End of the Euphoria - Latest Developments in the Greek (Old and New) Media Scene, from 2000 to 2011. Paper presented to the 16th International Conference on Corporate and Marketing Communications, The New Knowledge Globalization Era: Future Trends Changing Corporate and Marketing Communications. Athens: Athens University of Economics and Business 
Johnson, K. (2012). Audience Use of New Media Technologies on NPR.org. Journal of Radio \& Audio Media, 19:1.

Karamanis, Th. (2003). The Role of Cultural and Political Institutions in Media Policy: The case of TV Privatization in Greece. Cresskill: Hampton Press

Karathanasopoulou, E. (2014) An Examination of the Concept of Intimacyin Radio Studies, Combining Mainstream and NonMainstream Theories andPractices. Doctoral thesis, University of Sunderland. https://sure.sunderland.ac.uk/id/eprint/6792/. Accessed 7 February 2020.

Lacey, K. (2008). 'Ten Years of Radio Studies: The very idea'. The Radio Journal-International Studies in Broadcast and Audio Media, vol. 6, no. 1, 21-32.

Lacey, K. (2018). 'Up in the air? The matter of radio studies', Radio Journal - International Studies in Broadcast \& Audio Media, 16:2, pp. 109-26.

Lewis, P.M. \& Booth, J. (1989). The Invisible Medium: Public, Commercial and Community Radio. London Macmillan.

Markman, K. M. (2012). Doing radio, making friends, and having fun: Exploring the motivations of independent audio podcasters. New Media \& Society, 14(4), 547-565.

Mindradio.gr. https://www.pinterest.co.uk/mindradio/. Accessed 11 February 2020.

Peter M. Lewis (2000) British Radio Studies, Journal of Radio Studies, 7:1,153-160,

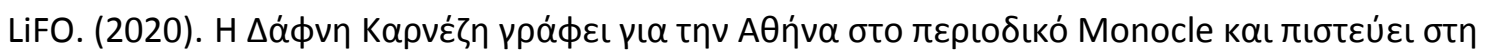

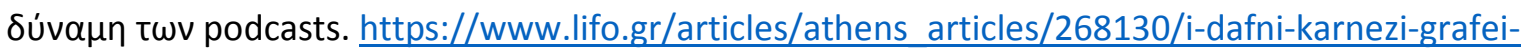
gia-tin-athina-sto-periodiko-monocle-kai-pisteyei-sti-dynami-ton-podcasts. Accessed 3 Feb 2020.

Llinares, D., Fox, N. \& Berry, R. (2018). Podcasting: New Aural Cultures and Digital Media. Cham: Palgrave Macmillan.

Markman, K. M. (2012). Doing radio, making friends, and having fun: Exploring the motivations of independent audio podcasters. New Media \& Society, 14(4), 547-565.

Melodia 99.2. (2020-). https://www.melodia.gr/programm/. Accessed 31 January 2020.

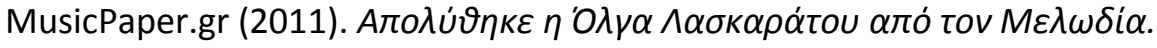

https://www.musicpaper.gr/reportage/item/422-2013-02-27-14-41-40. Accessed 8 February 2020.

Offradio.gr (2020). http://www.offradio.gr/playlist. Accessed 17 February 2020.

Oliveira, M., Stachyra, G. \& Starkey, G. (eds). (2014). Radio: The Resilient Medium: Papers from the third Conference of the ECREA Radio Research Section. Sunderland: Centre for Research in Media and Cultural Studies, University of Sunderland.

Papadopoulou, L. (2019). Democracy and media transparency: Systemic failures in Greek radio ecosystem and the rise of alternative and radical web radio. In: Chaparro Escudero, M., Gabilondo, V., \& Espinar Medina, L. (Eds). Transparencia mediática, oligopolios y democracia. Spain:

Comunicación Social: 211:219. 
Papathanassopoulos, S. (2018). Greece-Media Landscape. European Journalism Centre (EJC). Available at https://medialandscapes.org/country/greece. Accessed 30 January 2020.

Shingler, M. and Wieringa, C. (1998). On Air: Methods and Meanings of Radio. Arnold: London. Siapera, E., Papadopoulou, L. \& Archontakis F. (2015). Post-Crisis Journalism, Journalism Studies, 16:3, 449-465,

Siapera, E., Papadopoulou, L. (2016). Entrepreneurialism or Cooperativism? An exploration of cooperative journalistic enterprises. Journalism Practice: 10:2, 178-195.

Silberman, M. (2000). Bertolt Brecht on Film and Radio. Bloomsbury: London.

Sims. J. R., (2003) Politicians and Media Owners in Greek Radio: Pluralism as Diaplokí. Journal of Radio Studies, 10:2, 202-215

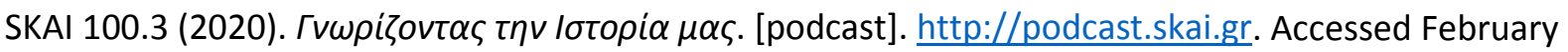
172020.

The Greek Podcast Project. (2020). https://www. podcastproject.gr/. Accessed 3 February 2020.

toradiofono.gr (2013) https://www.facebook.com/pg/toradiofono/about/?ref=page internal. Accessed 2 February 2020.

VanCour, S. (2016). Locating the Radio Archive: New Histories, New Challenges, Journal of Radio \& Audio Media, 23:2, 395-403.

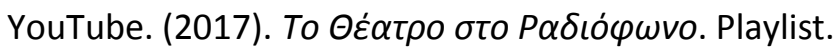

https://www.youtube.com/playlist?list=PL5D23BA75F91F1190. Accessed 9 February 2020.

\section{Interviews:}

Olga Laskaratou, Radio Producer - Presenter. Athens -Greece. February 2, 2020. 